\title{
“Ruim é copiar, é escrever": a escola para as crianças assentadas
}

\author{
"Bad is copying, it is writing": school for settled \\ children
}

\section{"Copier et écrire c’est mauvais": l'école pour les enfants sans terre}

\author{
Giana Amaral YAMIN
}

Roseli Rodrigues de MELLO

\begin{abstract}
RESUMO
Este artigo analisa os sentidos atribuídos à escola por crianças que estudam no Assentamento Nova Alvorada do Sul, em Mato Grosso do Sul (Brasil). A pesquisa - desenvolvida por meio da observação participante, da realização de entrevistas e da coleta de histórias de vida, revela como as dificuldades para concluir o processo de alfabetização e as condições objetivas delineiam (re)construções das expectativas escolares e da permanência dos meninos e das meninas assentados/as nos estudos. Finalizando, o texto apresenta reflexões que favorecem a discussão de uma proposta pedagógica para os espaços educacionais do campo e da cidade.
\end{abstract}

Palavras- chave: alfabetização - educação do/no campo =infâncías reforma agrária

\section{ABSTRACT}

This article investigates how children from Nova Alvorada do Sul Rural Settlement's (Brazil) understand and consider their school experience. Carried out by participant observation, interviews and a compilation of life histories, this study reveals how the students' life circumstances and the problems concerning their literacy process influence their school expectations and their permanence in the settlement. Therefore, while addressing these questions, this article can also encourage the discussion of pedagogical proposals for rural and urban educational spaces. reform

Index terms: literacy - rural education - childhood - agrarian 


\section{RESUME}

Cet article analyse les sens de l'école pour des enfants qui étudient dans un camp de l'état du Mato Grosso do Sud (Brésil). La recherche, développée au moyen d'observation, d'entretiens, et de colecte, d'histoires de vie révèle les difficultés pour conclure le processus d'alphabétisation et les conditions de vie des élèves qui modifient leurs besoins scolaires dans la vie quotidienne à la campagne. Pour terminer, le texte présente des réflexions qui favorisent la discussion d'une proposition pédagogique pour les espaces éducationnels à la campagne et à la ville.

Mots clés: alphabétisation; éducation de la/à la campagne; enfances; réforme agraire.

\section{Apresentação}

Este artigo aborda a realidade de uma escola localizada em um assentamento de reforma agrária, a partir dos sentidos atribuídos à escola por meninos e meninas que não conseguiram concluir seu processo de alfabetização. O tema foi desenvolvido por meio de um trabalho de doutorado $^{1}$, que identificou que as dificuldades que os alunos/as enfrentavam para aprender a ler e a escrever interferiam nas suas expectativas de presente e de futuro no espaço da reforma agrária.

A socialização da temática visa a contribuir para ampliar as discussões sobre as práticas de alfabetização, com vistas à formulação de currículos que considerem os anseios das populações rurais. Também pretende oferecer subsídios para repensarmos as políticas de educação do/no campo no Brasil, valorizando a voz das crianças.

O texto está dividido em seis itens. Inicialmente, resgata aspectos que relacionam a importância do processo de alfabetização para a consolidação dos assentamentos rurais. Na sequência, apresenta o universo da população assentada que participou da investigação, considerando a existência de crianças que vivem infâncias diferentes.

\footnotetext{
${ }^{1}$ Tese de doutorado, Crianças com-terra: (re) construção de sentidos da infância na reforma agrária. São Carlos: UFSCar, 2006.
} 
O terceiro item analisa os sentidos da escola veiculados por crianças, de idades diferentes, focalizando as práticas de alfabetização como elementos resignificadores das expectativas escolares e de futuro no âmbito da reforma agrária. Toda a problemática é retomada no item quatro, que reflete acerca da realidade do Assentamento investigado, focalizando os temas educação e alfabetização. Por fim, são apresentadas algumas propostas que intencionam indicar possibilidades de ação para refletirmos acerca da educação veiculada nas escolas do/no campo e da cidade.

\section{Os assentamentos e o processo de alfabetização}

A preocupação com a educação sempre esteve presente entre as ações da maioria dos movimentos sociais, já que a construção das "escolas de lonas" permite que as crianças continuem seu processo de escolarização formal. Isso as aproxima dos espaços de luta e fortalece a união familiar em torno do objetivo a ser conquistado.

Posteriormente, na condição de assentados da reforma agrária, a edificação das escolas continua sendo uma meta tão importante quanto o frutificar a "terra prometida". Em algumas instituições do Movimento dos Trabalhadores Rurais Sem-Terra/MST, por exemplo, as disciplinas enfocam a luta de classes, pautadas em Paulo Freire, Pistrak e Makarenko. Já a Comissão Pastoral da Terra/CPT, visualizando a terra como um dos bens doados aos filhos de Deus, atua na educação básica e na implantação das escolas técnicas, entre outras. Como ponto comum, as escolas procuram instrumentalizar os trabalhadores para o retorno à terra de trabalho.

As reivindicações a favor de uma educação que considere a realidade e as expectativas dos trabalhadores rurais foram desencadeadas por movimentos reivindicatórios que a visualizavam como subsídio para um projeto de sociedade construído pelas classes desfavorecidas (VARGAS, 2004). Para que isso fosse concretizado, enfrentaram a ideologia de que os 
trabalhadores rurais não precisariam ser alfabetizados por atuarem com o labor rudimentar (RICCI, 1999).

Essa discussão chegou ao Mato Grosso do Sul antes da sua divisão, resultando na implementação gradativa de políticas públicas (JESUS, $2002)^{2}$. Tal trajetória recebeu interferência da interligação firmada entre a terra e o poder no estado que, remetendo força social e política às oligarquias, influenciou o fazer das escolas rurais com intenções políticas, interferindo significativamente para o delineamento da realidade atual ${ }^{3}$ (SOUZA,1997), considerando que nem todas as escolas rurais desenvolvem ações pautadas nos idéias de luta preconizadas pelos movimentos sociais.

Em relação à alfabetização, as teorias que se opõem às práticas mecanicistas estão presentes nas escolas sul-mato-grossenses desde o final da década de 1980 - com a inserção de Piaget e de Paulo Freire nos documentos oficiais. Apesar disso, a mudança de paradigma tem sido lenta e é agravada no campo porque as crianças de tal meio são depositárias de preconceitos que tomam a distância e o isolamento geográfico como marcas de pessoas menos capazes.

A criação dos assentamentos rurais, decorrente dos conflitos no campo, no Brasil, sempre estabeleceu uma estreita relação com as práticas de alfabetização, à medida que, para os trabalhadores, ela é considerada como uma das ferramentas para a concretização do projeto almejado. Essa meta é observada em muitas experiências exitosas, que confirmam a contribuição social de um trabalho educativo pautado na realidade dos educandos - como as iniciativas da Escola Ativa, das Escolas Famílias Agrícolas, das Casas Familiares Rurais (BRASIL, 2003). Tais ações almejam uma escola que estabeleça “(...) uma relação com o desenvolvimento, supõe também que os sujeitos, que vivem e trabalhem

\footnotetext{
${ }^{2}$ No ano de 1996, foi criado Ensino Rural - Construindo uma proposta para Mato Grosso do Sul. Em 2000, a proposta Educação Básica no Campo foi gerada a partir de um projeto de educação popular em colaboração com a UNESCO, com movimentos sociais, sindicatos e Ongs (JESUS, 2002).

${ }^{3}$ Inadequação do currículo, do calendário, das metodologias, a inexistência de uma política específica às regiões, as dificuldades dos educadores (Governo do Estado do Mato Grosso do Sul, 2004).
} 
neste espaço, compreendam o campo como um lugar de viver e reproduzir a existência e não apenas de produzir para o mercado" (GHEDINI, 2009, p. $39)$.

Apesar do exposto, os índices da educação básica na zona rural ainda são permeados por uma alta taxa de distorção idade-série, com cerca dos $50 \%$ dos alunos com idade superior à adequada (BRASIL, 2003). Essa contradição reflete a dissociação da escola da cultura e das necessidades dos que vivem no campo (SILVA, B., 2004) e a inexistência da promoção do resgate social. Por isso, questionamos:

- qual o impacto da ineficácia das práticas de alfabetização para o tempo presente e de futuro das crianças assentadas? Quais serão as consequências de um ensino que se oponha às suas expectativas? E, finalmente, por onde delinear a construção de uma escola do/no campo?

Estas indagações são discutidas neste artigo, que desoculta os sentidos da escola das crianças assentadas a partir das contingências impostas por seu contexto: a luta pela subsistência, a distância da cidade, os obstáculos para construir seu futuro como agricultores familiares e a inexistência de uma política pública para atender sua especificidade. O processo de toda a pesquisa foi apoiado nos pressupostos de Vigotski, que discute os conceitos de sentido e de significado da palavra.

(...) o sentido de uma palavra é a soma de todos os eventos psicológicos que a palavra desperta em nossa consciência. É um todo complexo, fluido e dinâmico, que tem várias zonas de estabilidade desigual. O significado é apenas uma das zonas do sentido, a mais estável e precisa. Uma palavra adquire o seu sentido no contexto em que surge; em contextos diferentes altera o seu sentido. (VIGOTSKI, 2003, p. 181).

Assim, se a aprendizagem da linguagem escrita é significada como “(...) um processo de construção de conhecimento pelas crianças por meio de práticas que têm como ponto de partida e de chegada o uso da linguagem 
e a participação nas diversas práticas sociais" (BRASIL, 1998, p. 122), cuja apropriação exige um conjunto de processos de mediação de outros sujeitos e da linguagem (LURIA, 1988), o sentido que ela tem para as crianças é diferente, pois é construído nas condições práticas veiculadas nas instituições formais. Esses sentidos são apresentados na sequência, considerando a realidade das crianças de forma dialética, marcada “(...) por oposições, simetrias e assimetrias, enfim, tensões que se objetivam em sínteses inexoravelmente provisórias (...)”(ZANELLA et. al., 2007, p. 05).

\section{O universo e os atores da investigação}

A reivindicação pela implantação dos assentamentos de reforma agrária no Mato Grosso do Sul foi resultante da luta de classes. Em diferentes momentos históricos, a categoria criança sem-terra, posteriormente transformada em criança assentada, foi consolidada pela disputa do seu solo fértil, por intenções governamentais e pela intervenção de grileiros, posseiros e fazendeiros. Essa contextualização elucida a origem das causas sociais que as oprimem atualmente, muitas vezes ignoradas pelas classes desfavorecidas.

A investigação que subsidia esta discussão foi desenvolvida no Assentamento Nova Alvorada do Sul (PANA), localizado no município de Nova Alvorada do Sul, no estado de Mato Grosso do Sul. Foi pautada na observação participante, na análise de documentos e na história oral de vida de crianças e de adultos assentados pela reforma agrária há onze anos.

O PANA foi desapropriado no ano de 1997, após quatro anos de luta de um grupo sem-terra, liderado pela Comissão Pastoral da Terra. Abriga 86 famílias, cujo cotidiano é condicionado pelas consequiências da política de reforma agrária do nosso país: o descaso de autoridades, o atraso nos financiamentos, a desapropriação de uma terra infértil, a falta de apoio dos movimentos sociais, as imposições do mercado, entre outras. As crianças 
que vivem nesse espaço têm suas infâncias condicionadas por tais fatores, entre eles seu tempo de escola.

Observamos que no Assentamento existem muitas infâncias, cujas características são regidas pelos frutos que a terra lhes proporciona ou que lhes nega: infâncias vividas por filhos/as de trabalhadores rurais e por filhos/as de latifundiários, de meninos/as que convivem em acampamentos e de crianças moradoras nos lotes da reforma agrária. Todos têm suas vidas mediadas pela carência ou pela abundância de um pedaço de chão, voltado para o trabalho familiar ou para o lucro.

No momento da realização da investigação, as famílias assentadas refletiram acerca do trabalho desenvolvido pela escola a partir de suas condições objetivas e das necessidades dos filhos. De um modo geral, quando as crianças eram menores, os pais/mães preocupavam-se com a efetivação da etapa da aprendizagem das letras. Por isso, a escola era considerada uma oportunidade para garantir o futuro dos filhos/as.

Os dados aqui socializados foram delineados a partir dos depoimentos de alunos/as matriculados na Escola Municipal Comendador Luis Meneguel, que tiveram suas identidades preservadas. São crianças e jovens de quatro a quinze anos de idade, não alfabetizadas, que expressaram expectativas/questionamentos acerca da sua escola. Seus familiares e professores foram ouvidos, sendo seus depoimentos fonte de dados complementares.

A referida Instituição, além de atender a crianças assentadas, oferecia ensino médio e fundamental a alunos que moravam nas fazendas e em um acampamento sem-terra. Todos se deslocavam diariamente para assistir as aulas. Alguns enfrentavam as difíceis estradas durante um período de três horas. A interferência de seus familiares na luta contra a desigual distribuição do solo sul-mato-grossense os incluía na condição de agricultores familiares. 
Contudo, os resultados escolares e o alto índice de analfabetismo alteravam os seus sentidos da escola. Dessa forma, apesar de visualizarem que a independência dos filhos/as viria por meio dos estudos, a escola passava a ser concebida pelas famílias como uma opção desacreditada. Essa incerteza impulsionava nos pais/mães o incentivo para que os jovens se inserissem no mundo assalariado ou nos acampamentos sem-terra. Como consequiência, tal decisão gerava uma contradição: o trabalho por eles desempenhado era imprescindível ao lote familiar, considerando a chegada da velhice dos responsáveis, mas a impossibilidade de assalariamento e a pouca extensão da terra os impulsionava a buscar outros rumos às suas vidas.

Já os moradores que vivenciaram a experiência de luta com apoio da CPT, como lideranças sem-terra, se preocupavam com o fato de a Escola se distanciar do histórico e da valorização da reforma agrária. Por isso, temiam que seus filhos e filhas sentissem vergonha da causa sem-terra.

A base do ensino do colégio não vai ao encontro de nossos princípios. (...) A gente vem de uma luta que se uniu e foi em busca de dias melhores e quando um filho nosso fala, às vezes, têm professoras que até ignoram (Sr. Davi).

O ponto de vista dos educadores/as também foi considerado pela pesquisa, respeitando sua relação com o mundo da reforma agrária. As escolas rurais sul-mato-grossenses fazem parte do processo de luta pela terra no estado e os professores do PANA, apesar de suas histórias, compartilhavam sua dupla condição de funcionários públicos e de bovinocultores. Isso lhes imputava preocupações diversas, como os baixos salários, as políticas de educação, as dificuldades com a seca, os atrasos dos financiamentos, o preço do leite... Muitos eram oriundos das cidades. A maioria não vivenciou o movimento de luta pela desapropriação daquelas terras, por isso desconheciam a importância da discussão agrária na sala de aula. 
Por tudo isso, o currículo veiculado na Escola não contemplava as particularidades geralmente atribuídas às instituições do campo pelos movimentos sociais. Os professores/as acreditavam que seus alunos possuíam as mesmas capacidades das crianças da cidade ao mesmo tempo em que identificavam nelas algumas limitações pela falta de contato com o mundo urbano. E, entre as causas desencadeadoras do grande número de alunos repetentes e de não alfabetizados, os educadores/as apontavam o trabalho que as crianças executavam nos lotes e a ausência de ajuda da família nos deveres de casa como os fatores responsáveis pela não aprendizagem.

Além disso, entre os educadores, permeava uma indefinição a respeito da direção do trabalho a ser adotado pela escola: pautar o ensino em disciplinas convencionais e/ou em técnicas agrícolas? Mesclar um currículo regular somado às questões da desigualdade territorial no Brasil ou construir um currículo específico? Por onde começar tal discussão?

\section{O que as crianças pensavam da sua escola}

"Só sei ler uma palavra. Essa aí, não..."

As dificuldades em relação à aprendizagem da alfabetização foram evidenciadas como um problema para muitas crianças da escola investigada, resultando em um recorte importante para a pesquisa. Os alunos mais velhos desgostavam das atividades elaboradas pelos professores. Entre eles, Diogo $^{4}, 12$ anos, que refazia pela quarta vez a segunda série do Ensino Fundamental. Oito de seus colegas eram repetentes e a metade da turma não dominava a técnica da leitura.

Diogo e seu primo Fábio, 10 anos de idade, descreviam o ensino das letras como cansativo e com pouca ajuda: "Ela só escreve e não ensina. Ela lê, e não ajuda a gente ler". Como ponto negativo, os meninos apontavam o

\footnotetext{
${ }^{4}$ Os nomes das crianças que ilustram este trabalho são fictícios.
} 
excesso da cópia que eram obrigados a realizar: "A professora passa matéria no quadro. A gente copia. Ela passa coisa no quadro, a gente copia e, aí, ela passa coisa no quadro (...). Quando ela chega, passa mais matéria". Seus cadernos abarcavam um trabalho direcionado ao ensino dos conteúdos. Suas folhas estavam totalmente preenchidas de "matéria" copiada da lousa, mas sua interpretação era incompreensível, já que as crianças não estavam alfabetizadas: "Só sei ler essa palavra aí. Essa outra não" (Diogo).

As atividades planejadas para otimizar o processo da alfabetização das crianças eram subsidiadas por treinos de fixação das sílabas, enfatizando os exercícios de aprendizagem da escrita com enfoques preparatórios, que, por sua vez, não desencadeavam resultados positivos. Esse modelo era estendido aos alunos na sala da Educação Infantil. Nessa turma, os meninos e as meninas, de 04 a 06 anos de idade, vivenciavam precocemente uma rotina escolarizante.

Muitas iniciativas propostas para o ensino da leitura eram desenvolvidas mecanicamente, apenas por meio da repetição. Para estudar as vogais, por exemplo, a folha mimeografada pedia que as crianças relacionassem o desenho de um ônibus ao treino motor da letra "O". Elas coloriram o desenho e repetiram o traçado maiúsculo da inicial, completando cinco linhas. Tal tarefa não oferecia sentido lingüístico. Uma das meninas, Bianca, interpretou as letras "Os" como sendo os "pneus" do veículo. Desinteressados, os pequenos caminhavam pela sala, conversavam, sentavam embaixo da mesa. Em determinados momentos, rabiscavam e rasgavam a folha que continha uma proposta cujo signo estava desligado da função social de comunicação. Tais comportamentos evidenciavam sua negativa avaliação da escola, pois assim como ocorria com os/as meninos/as mais velhos/as, escrever dessa forma desagradava.

Ligada a essa concepção mecanicista da alfabetização, a Escola do PANA destinava pouco tempo para que as crianças pudessem brincar, 
desconsiderando a contribuição dessa atividade para o processo de construção do seu psiquismo, como discute Vigotski. O brincar era restrito aos breves momentos do recreio, da aula de educação física e do trajeto vivenciado dentro do ônibus escolar.

Concomitantemente, o trabalho desenvolvido pelas crianças no espaço doméstico, que exigia tempo e dedicação de algumas delas, e a situação de analfabetismo dos familiares as afastava cada vez mais da possibilidade de conseguir aprender a ler e a escrever. Assim era o cotidiano de Diogo e Fábio, que desabafaram: “A gente trabalha mais aqui no sítio do que brinca. O pai vai dormir e nós brincamos. Quando ele acorda, manda a gente tocar as vacas. A gente vai, toca, toma banho e vai dormir".

Por isso, a partir dos 04 anos de idade, desde a Educação Infantil, alguns alunos/as iam construindo dois sentidos da escola: o de um lugar onde deveriam ficar sentados esperando a professora "passar" atividades que deveriam ser copiadas, mas que, ao mesmo tempo, lhes permitia uma certa distância dos serviços executados nos lotes familiares.

"Não sei matemática, só que tenho nota boa...".

Além das questões relacionadas à alfabetização, no ambiente da pesquisa foram evidenciados alunos com dificuldades para a realização de cálculos matemáticos elementares. Entre elas, Adriana, sétima série, desconhecia a tabuada e a lógica do processo que a ajudaria a efetuar a operação da divisão.

Seu êxito nas avaliações escolares era resultante das provas com consulta e da reprodução dos exercícios realizados pelos colegas. Assim como o ensino da leitura e da escrita, seu professor desenvolvia o trabalho com os cálculos matemáticos de forma mecânica esquecendo-se que, como qualquer atividade, a disciplina não pode ser ensinada por meio de definições verbais por estar presente nas experiências cotidianas. Essas dificuldades poderiam ser alteradas com a reavaliação dos processos pedagógicos que enfatizam o acúmulo de conceitos matemáticos e da escrita 
de forma descontextualizada, já que esses não previam “(...) qualquer relação autônoma com o mundo e não respondem a qualquer exigência particular" (LEONTIEV, s.d, p. 315).

A opção por um trabalho didático pautado nos moldes behavioristas não é uma exclusividade dessa escola rural. É resquício de funções educativas no país, voltadas a conter índices de fracasso escolar, uma intenção que se enquadra no ensino do desenho das letras, que, na perspectiva de Vigotski (2000), obscurece a linguagem escrita.

Especialmente, em relação às crianças que estudavam na Educação Infantil, seria importante que elas tivessem a oportunidade de experenciar situações que envolvessem a leitura e a escrita, já que possuem capacidade para interagir com a linguagem. Tal ensino deveria ser organizado de forma que o ler e o escrever fossem atividades necessárias e que a ação de alfabetizar considerasse a escrita como a fala em pensamento/ imagem. Isso requereria, por parte dos alunos, uma ação analítica da estrutura sonora das palavras, da sua dissecação e reprodução em símbolos, em determinada sequência. Nesse processo, seria fundamental a presença de um motivo, isto é, de uma necessidade para a utilização da tarefa de ler e de escrever (VIGOTSKI, 2003), distante da prática, de copiar e repetir sílabas, observada.

\subsection{O ambiente da Sala Especial}

Ao lado do Posto de Saúde, a Escola Municipal Comendador Luis Meneguel contava com uma pequena sala para atender as crianças com necessidades especiais. No momento da investigação, duas professoras trabalhavam com seis alunos/as com idades e características diferentes. Eles/as não haviam sido avaliados neurologicamente e as responsáveis, apesar de acreditarem no seu potencial para participar da etapa da alfabetização, não sabiam como potencializar tais aprendizagens. 
A sala de aula era organizada com seis jogos de carteiras, um armário, uma lousa pequena, uma mesa para a professora e um banheiro. Esporadicamente, os alunos participam dos momentos de recreio e das festividades que a escola organizava.

Mesmo sem conseguir se comunicar verbalmente com clareza, as crianças criavam mecanismos de resistência para afastar as tarefas indesejadas e para externalizar seus sentidos da escola. Suas inquietações expressavam desagrado em relação às atividades propostas e ao tempo dispensado à sua execução. A agitação e a intenção de fugir (a porta da sala ficava trancada) significavam que as tarefas de picar papel, amassar revistas, colar bolinhas de crepom, manusear aleatoriamente palitos de picolé e livros velhos eram desinteressantes e que extrapolavam o tempo suportável de concentração.

Apesar disso, em muitas ocasiões, os alunos revelaram gostar da escola, pois não manifestavam agitação ou vontade de ir embora. Isso ocorreu durante as aulas-passeio, quando jogaram bola, nos momentos que foram exploradas as várias linguagens (estórias, música, rodas, quando corriam ou sopravam bolhas de sabão). Os alunos demonstravam que sentiam prazer nessas situações e que elas desencadeavam aprendizagens.

As práticas educativas voltadas à Educação Especial no ambiente da pesquisa vinculam-se à cultura escolar construída no nosso país. Historicamente, os critérios que têm guiado o planejamento das atividades têm sido movidos por uma leitura que gera desigual distribuição de conhecimentos, que desvaloriza a escolarização como o elemento definidor de possibilidades de socialização/integração desses alunos. Consequentemente, as crianças assentadas acabavam centradas em moldes técnicos, relegando as aprendizagens dos educandos e enfatizando suas características "anormais", impedindo real aprendizado, incluindo aqueles inerentes ao processo de alfabetização, que abarcam a exploração das várias linguagens. 
Nesse sentido, sinalizamos, subsidiadas em Silva (2000), que, para julgar as possibilidades de uma aprendizagem efetiva dessas crianças e jovens, seria necessário reconhecer que o seu desenvolvimento ocorre de maneira peculiar, não inferior. Seria preciso visualizá-los como sujeitos ativos e isso culminaria com uma ação educativa que fosse capaz de romper com as práticas mecanicistas. Além disso, a formação e um diagnóstico profissional deveriam subsidiar a ação das educadoras. Elas deveriam ter condições de refletir sobre quem são seus alunos, como eles aprendem e quais são suas potencialidades. Precisariam receber um suporte que lhes permitisse se distanciar do estigma de sua deficiência, trabalhando os conhecimentos, possibilitando a apropriação das formas sociais de organização do real, considerando o conceito de Zona de Desenvolvimento Próximo (VIGOTSKI, 2004).

\section{A educação do/no assentamento e a alfabetização: algumas reflexões}

A pesquisa revela que no assentamento investigado as expectativas das famílias em relação à escola vão se alterando a partir das transformações que perpassam as suas vidas: suas condições de sobrevivência, as determinações da política de reforma agrária, a faixa-etária e o resultado escolar dos filhos.

Verifica-se que os sentidos da escola são diferentes dentro de uma mesma família - vinculados às questões educacionais, de gênero e ao número de filhos. Muitos pais incentivam a escolarização das meninas ao mesmo tempo em que apóiam o investimento do menino (futuro provedor do lar) em outra atividade.

Da mesma forma, a ausência de um trabalho coletivo entre os/as assentados/as, o afastamento do movimento social, a formação dos educadores, o distanciamento da Secretaria de Educação, a necessidade de envolver as crianças no trabalho do lote e as condições de sobrevivência interferiam na ação desencadeada pela educação formal. Também eram 
fatores que contribuíam para avaliação que as famílias faziam da Escola. Para os adultos, a Instituição era vista como uma opção fundamental, mas, com o passar do tempo, adquirir um pedaço de terra por meio da reforma agrária passava a ser apontado como a 'salvação' para o futuro dos filhos/as, já que a escola não cumpria sua função de 'ensinar a ler e a escrever'.

Diante dos problemas evidenciados, é fundamental reconhecer a ausência da participação de todos os segmentos ${ }^{5}$ nas decisões escolares. Assim como nos ambientes urbanos, a escola deveria propor a desconstrução da visão utilitarista dos conteúdos obrigatórios e dos da vida. Isso demandaria a alteração das relações sociais, calcadas na organização individual. Como conseqüência, seria preciso valorizar a vida dos estudantes no ambiente rural, repensar a adoção do modelo da criança urbana e adotar metodologias que considerassem os ritmos e as potencialidades dos alunos (não suas incapacidades).

Outro ponto fundamental são as diferenças entre os objetivos das propostas pedagógicas idealizadas pelos movimentos sociais ${ }^{6}$ e as expectativas dos assentados. Observamos que, para as famílias, o esforço do trabalho na terra não era movido por objetivos de transformação social, mas por necessidades de sobrevivência nessa terra- como saldar financiamentos, modernização, ampliar o patrimônio e adquirir bens. $\mathrm{O}$ mesmo acontecia com suas expectativas em relação à escolarização dos filhos/as. Tendo como aporte Luria (1990), constatamos que essa contradição resultava da satisfação de novas metas/potencialidades da condição de ser um com-terra, que desencadeava novos motivos para ações - criando problemas, comportamentos, métodos de captar informações e reflexos da realidade.

Ressaltamos que toda essa discussão não intenciona responsabilizar os educadores/as pela situação encontrada. Embora necessitassem de reavaliações metodológicas, não podemos esquecer que eles/as também

\footnotetext{
${ }^{5}$ Família, comunidade, crianças, movimento social, município.

${ }^{6}$ Relacionados à luta das classes populares, ao questionamento dos valores capitalistas e das divisões hierárquicas entre o trabalho braçal e intelectual.
} 
eram sujeitos assentados preocupados com a sobrevivência, cuja atuação estava vinculada às suas condições no campo. Em todas as etapas da pesquisa, convivemos com profissionais que apresentavam atitudes responsáveis, preocupadas e atentas com relação às dificuldades e às particularidades das crianças. Tal constatação, contudo, não miniminiza as consequências e a reflexão acerca dos problemas existentes.

A Escola do PANA - assim como seria com qualquer escola urbana assumia para as famílias o sentido da exclusão quando não conseguia alfabetizar, quando dificultava a construção dos conhecimentos, quando mantinha as crianças da sala especial na única meta da socialização e quando apenas "preparava" os meninos e meninas pré-escolares para alfabetização. Nesse ciclo, eram prejudicados professores e alunos. Os primeiros por não se beneficiarem da atividade por eles realizada e os últimos por serem privados da apropriação dos conhecimentos adquiridos pela humanidade.

Na situação vigente, a imersão da escola em uma política pública, que não se preocupa com o futuro dos filhos com-terra, impedia que eles pudessem optar entre permanecer ou não na "terra prometida". Por isso, os alunos tinham dificuldades para inserirem-se no mercado de trabalho urbano devido à sua pouca qualificação. Sentiam-se discriminados e "condenados" pela sua "incompetência instrucional". Consequentemente, procuravam os bancos das universidades particulares. Imperioso destacar que a busca pelo acesso a um pedaço de chão deveria ser uma opção dos jovens, jamais a única opção em caso de um possível insucesso escolar.

Ao analisar a conjuntura da educação rural, é fundamental, ainda, desocultar as diferenças sociais no campo e na cidade. A criança com-terra precisaria reconhecer-se como categoria histórica para conseguir se identificar como um assentado rural. A educação do campo deveria discutir os conflitos da realidade local, permitindo que os alunos adquiram gradativa força e coragem para lutar contra sua realidade, como preconiza Freire 
(1980). Se isso não for efetivado, correremos o risco de que eles acabem aprisionados em situação inviável por desconhecerem os conhecimentos historicamente organizados, pela ausência de perspectivas de futuro e pela imposição da sobrevivência em um assentamento economicamente impossível. Esse aprendizado não é fácil. Exigirá uma (re)organização comunitária, o respeito pela opinião do outro, a presença do diálogo, entre outros fatores.

\section{Reflexões para repensarmos o trabalho das escolas do campo e da cidade}

Nossa pesquisa revela que a educação no Assentamento PANA era permeada por aspectos (gerais e particulares) que caracterizam sua especificidade no âmbito educacional sul-mato-grossense.

Discutindo os aspectos gerais, visualizamos que o mesmo olhar e as mesmas ações que direcionam uma escola localizada na zona urbana devem permear o fazer educacional das escolas do campo. Nos dois espaços, existem problemas, ideologias, carência de recursos, crianças com especificidades. Nos dois ambientes, os educadores necessitam dominar conhecimentos que direcionem ações promotoras do acesso ao saber sistematizado e devem ser munidos de informações acerca da luta de classe no Brasil. Com as devidas especificidades, os professores da cidade ou do campo devem considerar que seus alunos/as são capazes de produzir cultura e que merecem uma avaliação acerca dos conteúdos, da ideologia e da metodologia nos quais serão envolvidos/as.

Nesse sentido, as escolas precisam repensar posicionamentos que direcionam o "ensino das letras e dos números": a ênfase na cópia e no simbolismo, a parca utilização da integração dos temas da organização linear do currículo e desconsideração da mediação do professor para a reelaboração dos conteúdos. Igualmente, os conteúdos e as práticas da alfabetização deveriam ser articulados com seus cotidianos, aproximando as 
crianças da apropriação dos conceitos científicos, que têm, segundo a teoria vigotskiana, importantes implicações para a educação.

Também seria importante conduzir os alunos ao estabelecimento de relações entre conceitos que contemplassem a aquisição de diferentes formas de perceber a realidade e a ampliação das idéias que elas têm a respeito do mundo (MIGUEL, 2003).

Acreditamos que os dois espaços precisam encontrar formas de consolidar seu trabalho numa concepção de alfabetização enquanto processo, favorecendo a exploração de outros ambientes educativos (FARIA, 1999), já que “(...) o ensino tem que ser organizado de forma que a leitura e a escrita se tornem necessárias (...)” (VIGOTSKI, 2000, p. 155). Com base em Vigotski (2003), percebemos que o processo de desenvolvimento da escrita exige uma abstração por parte do aprendiz, pois é uma fala sem interlocutor, que o obriga “(...) a criar uma situação, ou a representá-la para nós mesmos. Isso exige um distanciamento da situação real" (idem p. 124). Além disso, o processo de alfabetização deve ser precedido pela possibilidade de brincar, de desenhar e que permita o registro iconográfico.

Independentes do lugar onde estejam localizadas, todas as instituições educativas, da cidade ou do campo, devem construir seu projeto educativo e decidir sob que bases irão apoiar sua ação. E, caso seja acatada uma visão crítica (a busca por uma educação voltada à resolução dos problemas), o trabalho com os conteúdos será essencial, pois propiciará uma reflexão acerca da realidade de inserção, a fim de se aproximá-los da humanização. Tal demanda impõe que as escolas executem sua imperiosa função de trabalhar eficazmente tais saberes.

Complementando a visão geral da educação, como o aprendizado das crianças não é idêntico (VIGOSTKI, 1998), ressaltamos que a ênfase da alfabetização deverá incidir sobre suas capacidades. Será preciso considerar que eles lêem o mundo e aprendem em várias instâncias, a partir de ações 
partilhadas com o outro - internalizando conceitos, valores, sentimentos, por meio da mediação de instrumentos, dos símbolos e da linguagem de forma real, não da maneira como está ocorrendo.

Esse raciocínio demanda um bom trabalho de alfabetização que se adiante ao desenvolvimento, o que implicará na intervenção de um professor experiente, na sua aproximação das crianças com quem trabalha e na valorização das trocas de diferentes culturas, idéias e valores (VIGOSTKI, 2003). Nesse aspecto, a ação sobre a zona de desenvolvimento próximo incidirá na redefinição das práticas da imitação e do brincar, tão pouco veiculadas nas séries iniciais, em nome da necessidade de ensinar o código escrito. Tal ação transformará os conceitos espontâneos das crianças por meio de ações significativas a elas.

Encerrando os pontos comuns entre os aspectos que devem direcionar todas as escolas, a partir de agora, centramos a discussão em alguns aspectos particulares das escolas d/no campo.

Uma das questões a serem consideradas é a estreita relação entre os mundos rural e urbano: da cidade muitos assentados vièram e nela eram envolvidos para a comercialização dos produtos; na cidade, são realizadas as compras, a efetivação de financiamentos, as decisões políticas, a busca do trabalho, as consultas médicas e a frequência ao ensino superior. Por isso, persistir lutando $N A$ terra não afasta os assentados da zona urbana. Ao contrário, é uma realidade que, se continuar negligenciada, aumentará a exclusão dessa população da garantia de seus direitos sociais.

Ademais, embora a política de fixação do homem no campo amenize conter as intenções de migração existentes em nosso país (MARTINS, 2005), atualmente, ela se direciona a implantar o sistema de agricultura familiar como meio de vida/trabalho para atores condenados à miséria/indigência nas grandes cidades. Consequentemente, tal imposição demanda um olhar da escola e das práticas de alfabetização que contemple as questões urbanas e rurais simultaneamente. 
Elaborar um currículo para o campo exija o resgate de particularidades presentes nas estruturas das escolas rurais, também demanda a participação organizada, crítica e política da comunidade, permitindo a construção autônoma de práticas de conhecimento, evitando a reprodução da dominação por meio da uma transposição ideológica (FREIRE; NOGUEIRA, 1993). Por isso, apontamos como necessidade:

- $\quad$ Considerar as aprendizagens adquiridas pelos sujeitos antes e depois do assentamento. Reconhecer que, $\underline{\text { se }}$ as crianças assentadas foram parceiros importantes na luta PELA terra, após essa conquista elas se configuram como parceiros fundamentais na luta pela PERMANÊNCIA da família nos lotes. Isso significa que as crianças e os jovens têm uma história de vida e que possuem hábitos culturais reconstruídos que diferenciam suas especificidades, mas, jamais os inferiorizam. Depois de assentadas/os, elas/es continuam aprendendo: vivenciam aprendizagens nos lotes, internalizam conhecimentos e experiências que, de acordo com a psicologia materialista, promovem mudanças nas suas operações intelectuais/motoras. Por isso, têm uma rica visão de mundo que deverá ser ampliada.

- Considerar que, se os conteúdos veiculados na escola do/no campo podem abarcar o ensino de técnicas agrícolas, os alunos têm o direito de se apropriar de conhecimentos que lhes permitam o acesso ao ensino superior, caso essa seja a meta de suas vidas. A ferramenta da alfabetização é o motor fundamental para subsidiar essa necessidade, desde que a escrita tenha sentido e seja incorporada como uma tarefa necessária e relevante para a vida, como preconiza a psicologia histórico-cultural.

- Ter em mente que a luta contra a exclusão abarca o oferecimento de um ensino de qualidade como direito estabelecido a todos os cidadãos. Por isso, da mesma forma que é insuficiente e excludente uma família possuir um pedaço de terra por meio de políticas de reforma agrária sem contar com os meios para viver nela de forma digna, é infundada 
apenas a permanência em sala de aula de uma criança que não compreende o que está sendo ensinado. Tal situação engrossa índices de programas governamentais inoperantes e escamoteia uma falsa inclusão social.

Salientamos que, mesmo que esperar "cansasse muito" e que a aprendizagem das letras fosse "complicada", os meninos e as meninas gostavam de frequentar a escola do Assentamento. Além da sua voz, isso pode ser evidenciado nos momentos de carinho com as professoras, quando riam e brincavam no difícil trajeto lote-escola, quando executavam suas pinturas, participavam da leitura de histórias, nas atividades ao ar livre, nas aulas de educação física e nos momentos de recreio. Enfim, quando não estavam "escrevendo ou copiando" coisas sem sentido, afinal "Ruim é copiar, ruim é escrever" (Diogo). Os motivos dessa contradição foram esclarecidos nas suas condições de vida e na organização da Instituição.

Frente ao exposto, embora tenha sido evidenciada por excelência como sendo o ponto centralizador de um ambiente particularmente das crianças, a Escola do Assentamento (e todas as outras) precisa extrapolar esses momentos de prazer para o desencadeamento de momentos de aprendizagem com prazer, desde a etapa da alfabetização. Para isso, deve receber apoio para que consiga planejar estratégias que desencadeiem o desenvolvimento das funções psicológicas superiores das crianças. Caberá ao professor, no ato de alfabetizar, a extrapolação dos momentos positivos de encontro/contato/afeto para efetivar a atividade do ensinar, uma implicação fundamental para superarmos os condicionamentos históricos da infância com-terra.

\section{Referências bibliográficas}


BRASIL, Ministério da Educação (2003). Referências para uma política nacional de educação do campo. Caderno de subsídios. Brasília, out.2003.

BRASIL, Ministério da Educação (1998). Referenciais curriculares nacionais para a educação infantil. Introdução. Brasília, DF: MEC: SEF.

FARIA, Ana Lucimar G. de (1999). O espaço físico como um dos elementos fundamentais para uma pedagogia da educação infantil. In: ; PALHARES, Marina Silveira (org). Educação infantil pós-LDB: Rumos e desafios. São Carlos: Universidade Federal de São Carlos, p. 6798.

FREIRE, Paulo (1980). Educação como prática de liberdade. 10 ed. Rio de Janeiro: Paz e Terra.

FREIRE, Paulo; NOGUEIRA, Adriano (1993). Que fazer? Teoria e prática em educação popular. 4 ed. Petrópolis:Vozes.

GHEDINI, Maria Cecília (2009). Educação do campo: história e processo na luta por direitos. In: MENEGAT, Alzira et al. Educação, relações de gênero e movimentos sociais: um diálogo necessário. Dourados-MS: UFGD, p. 25-42.

JESUS, Valdirene Gomes dos Santos de (2002). Educação Rural de MS: uma análise histórica. Dissertação (Mestrado), Universidade de São Carlos, (SP).

LEONTIEV, Aléxis (s.d). O desenvolvimento do psiquismo. São Paulo. Moraes Editora.

LURIA, A. R (1990). Desenvolvimento cognitivo. Seus fundamentos culturais e sociais. 2 ed. São Paulo: Ícone.

LURIA, A.; LEONTIEV, A. N (1988). Linguagem desenvolvimento e aprendizagem. São Paulo: Ícone. Editora da Universidade de São Paulo.

MARTINS, José de Souza (2005). Educação rural e o desenraizamento do educador. Revista Espaço Acadêmico, n. 49, jun.

MIGUEL, José Carlos (2003). O processo de formação de conceitos em matemática: implicações pedagógicas. 2003. Disponível em http://<www.anped.br. Acesso em: 05 jun. 
RICCI, Rudá (1999). Esboços de uma nova concepção de educação do meio rural brasileiro. Disponível em: < http://www.serrano.neves.nom.br/dowloads/educrural.pdf.> Acesso em 20 mai. 2005.

SILVA, Fabiany de Cássia Tavares (2000). Processos de ensino na educação dos deficientes mentais. Disponível em: <www.anped.org.br>. Acesso em: 01 jun. 2004.

SOUZA, Cláudio Freire de (1997). Terra e poder em Mato Grosso do Sul - As alianças políticas e os projetos de educação. Tese (Doutorado). Piracicaba: Universidade do Estado de São Paulo.

VARGAS, Maria Cristina (2004) Uma história em construção: EJA no campo.

<http://www.tvebrasil.com.br/salto/boletins2004/eja/tetxt4.htm>.Acesso em 12 dez 2005.

VIGOTSKI, L. Semenovich (1998). Aprendizagem e desenvolvimento intelectual na idade escolar. In: LURIA, A.R.; LEONTIEV. Linguagem, desenvolvimento e aprendizagem. 6 ed. São Paulo: Ícone: USP, p. 103117.

VIGOTSKI, L. Semenovich (2000). A formação social da mente. 3 ed. São Paulo: Martins Fontes.

VIGOTSKI, L. Semenovich (2003). Pensamento e linguagem. 2 ed. São Paulo: Martins Fontes.

VIGOTSKI, L. Semenovich (2004). O problema da consciência. In: 189. . Teoria e método em psicologia. São Paulo: Martins Fontes, p. 171-

ZANELLA, Andréa Vieira et al (2007). Questões de método em textos de Vygotsky: contribuições à pesquisa em psicologia. Disponível em http://<www.scielo.com.br>. Acesso em 05 jan. 2008. 


\section{Autoras:}

Giana Amaral Yamin

Professora da Universidade Estadual de Mato Grosso do Sul

Contato: giana@uems.br

Roseli Rodrigues de Mello -

Professora da Universidade Federal de São Carlos

Contato: roseli@ufscar.br

\section{Como citar este artigo:}

YAMIN, Giana Amaral e MELLO, Roseli Rodrigues de. "Ruim é copiar, é escrever": a escola para as crianças assentadas. Revista ACOALFAplp: Acolhendo a Alfabetização nos Países de Língua portuguesa, São Paulo, ano 4, n. 8, 2010. Disponível em: <http://www.acoalfaplp.net>. Publicado em: março - setembro de 2010

Recebido em março de 2009./ Aprovado em junho de 2009. 